\title{
Sosialisasi Konsep Lahan Pertanian Pangan Berkelanjutan Di Kecamatan Batang Tuaka, Kabupaten Indragiri Hilir
}

\author{
Mulono Apriyanto ${ }^{1}$, KMS. Novyar Satriawan Fikri ${ }^{2}$, Ali Azhar ${ }^{3}$ \\ Program Studi Teknologi Pangan, Fakultas Pertanian, Universitas Islam Indragiri, Indragiri Hilir, \\ Indonesia \\ ${ }^{2,3}$ Program Studi Ilmu Hukum, Fakultas Hukum, Universitas Islam Indragiri, Indragiri Hilir, Indonesia \\ Email: ${ }^{1}$ mulonoapriyanto71@gmail.com, 2novyarsatriawan3@gmail.com, ${ }^{3}$ sahabat.aliazhar@gmail.com
}

\begin{abstract}
Availability of land for agriculture is an absolute requirement to achieve self-reliance, security and food sovereignty. However, Indonesian farmland tends to decline due to land conversion. Therefore, determining sustainable food farmland and regulating the conversion of food farmland is one of the most strategic policies to achieve food security. The Spatial Plan of the Province of Riau in the Spatial Pattern Plan section states that one of the areas focused on wetland agriculture (rice) is Indragiri Hilir Regency. However, the high conversion of agricultural land threatens the survival of Sustainable Food Agricultural Land. Since the LP2B policy is very dependent on the willingness of the farmers who own the fields, it is considered necessary to socialize the concept of this LP2B policy among farmers so that they can support government policy in achieving food sovereignty. The results of the analysis show that Batang Tuaka sub-district has the potential to be used as Sustainable Food Agricultural Land (LP2B), but unfortunately this is not supported by farmers' knowledge and understanding of the LP2B concept, so the conversion of farmland is becoming more common and can threaten the realization of food security in Indragiri Hilir Regency.
\end{abstract}

Keywords: Food land, LP2B, Indragiri Hilir, land conversion.

\begin{abstract}
Abstrak
Ketersediaan lahan untuk pertanian merupakan syarat mutlak untuk mencapai kemandirian, ketahanan, dan kedaulatan pangan. Namun, lahan pertanian Indonesia cenderung menurun akibat alih fungsi lahan. Oleh karena itu, penetapan lahan pertanian pangan berkelanjutan dan pengaturan konversi lahan pertanian pangan merupakan salah satu kebijakan yang paling strategis untuk mencapai ketahanan pangan. Rencana Tata Ruang Wilayah Provinsi Riau pada bagian Rencana Tata Ruang Wilayah menyebutkan bahwa salah satu daerah yang fokus pada pertanian lahan sawah (padi) adalah Kabupaten Indragiri Hilir. Namun, tingginya konversi lahan pertanian mengancam keberlangsungan Lahan Pertanian Pangan Berkelanjutan. Karena kebijakan LP2B sangat bergantung pada kemauan petani pemilik lahan, maka dirasa perlu untuk mensosialisasikan konsep kebijakan LP2B ini kepada petani agar dapat mendukung kebijakan pemerintah dalam mewujudkan kedaulatan pangan. Hasil analisis menunjukkan bahwa Kecamatan Batang Tuaka memiliki potensi untuk dijadikan Lahan Pertanian Pangan Lestari (LP2B), namun sayangnya hal tersebut tidak didukung oleh pengetahuan dan pemahaman petani terhadap konsep LP2B, sehingga terjadi konversi lahan pertanian. menjadi lebih umum dan dapat mengancam terwujudnya ketahanan pangan di Kabupaten Indragiri Hilir.
\end{abstract}

Kata Kunci: Lahan pangan, LP2B, Indragiri Hilir, alih fungsi lahan. 


\section{A. PENDAHULUAN}

Indonesia adalah negara agraris, dengan luas daratan kurang lebih 190,9 juta ha. Dari keseluruhan luasan tersebut, 37,1 \% telah dimanfaatkan untuk kegiatan budidaya, seperti sawah, pertanian lahan kering, perkebunan, ladang dan penggunaan lainnya, sedangkan $62,9 \%$ lainnya berupa hutan. Dengan adanya pertambahan jumlah penduduk yang terus meningkat ini, dibarengi dengan pertumbuhan ekonomi dan industri, menimbulkan konversi lahan pertanian. Pola konversi lahan berdasarkan analisis perubahan penggunaan tanah dalam kurun waktu 1994-2014 terdiri dari penyusutan tanah hutan dan penggunaan tanah lainnya. Konversi lahan banyak terjadi di Jawa. Selama periode 1979-2013 tercatat seluas $625.459(38,43 \%)$ atau 31.273 ha/tahun lahan sawah di Jawa telah terkonversi. Alih Fungsi Lahan adalah suatu proses perubahan penggunaan lahan dari bentuk penggunaan tertentu menjadi penggunaan lain misalnya ke non pertanian, dan biasanya dalam pengalih fungsiannya mengarah ke hal yang bersifat negatif bagi ekosistem lingkungan alam sawah itu sendiri. Alih fungsi lahan terjadi sebagai akibat pertumbuhan ekonomi dan pertambahan jumlah penduduk yang terus meningkat (Apriyanto et al., 2021; Apriyanto \& Fikri, 2021; Azhar, Maryanto, Apriyanto, et al., 2020).

Kombinasi pertambahan penduduk dan konversi lahan pertanian menjadi permukiman dan kegiatan non pertanian lainnya telah menjadi ancaman tersendiri dalam penyediaan pangan. Keterbatasan luas lahan juga berakibat pada kinerja para petani yang hanya menggarap sedikit lahan dengan kesejahteraan yang rendah. Pertanian harus menghasilkan pangan sangat besar dengan penduduk Indonesia yang terus bertambah (Anonim, 2013). Hal tersebut tercermin dari pertumbuhan aktivitas pemanfaatan sumber daya alam yang didorong oleh meningkatnya permintaan kebutuhan terhadap penggunaan lahan serta adanya pergeseran kontribusi sektorsektor pembangunan primer, khususnya dari sektor pertanian dan pengolahan sumber daya ke sektor sekunder (manufaktur) dan sektor tersier (jasa) (Azhar, Maryanto, \& Siregar, 2020).

Berkurangnya lahan pertanian selama empat tahun terakhir (2013-2016) seluas 75.000 hektar tentu menjadi masalah tersendiri dalam perwujudan kebijakan lahan pertanian pangan berkelanjutan di Provinsi Riau. Salah satu wilayah yang direncanakan sebagai kawasan pertanian lahan basah adalah Kabupaten Indragiri Hilir. Secara statistik, di tingkat Provinsi Riau, Kabupaten Indragiri Hilir berada di posisi keempat sebagai penghasil beras setelah Kabupaten Siak. Kabupaten Indragiri Hilir memiliki posisi yang strategis sebagai wilayah yang berbatasan langsung dengan Propinsi Jambi dan Propinsi Sumatera Barat, sehingga sangat rentan terhadap alih fungsi lahan pertanian (Apriyanto et al., 2020; Novyar Satriawan Fikri \& Azhar, 2020).

Penelaahan awal menunjukkan Kecamatan Batang Tuaka merupakan salah satu wilayah dengan laju konversi lahan yang cukup tinggi di Kabupaten Indragiri Hilir sehingga dapat mengancam terwujudnya ketahanan pangan Kabupaten Indragiri hilir, lebih jauhnya terhadap ketahanan pangan Provinsi Riau. Karena itu dibutuhkan sosialisasi mengenai konsep LP2B kepada para petani pemilik lahan sehingga mereka dapat mendukung kebijakan tersebut dan mewujudkan kedaulatan pangan di Kabupaten Indragiri Hilir (Apriyanto \& Fikri, 2021; Djatmiko et al., 2019).

Tiga fungsi utama lahan sawah yaitu Pertama, fungsi yang menopang produksi pangan, lahan, air, praktek bercocok tanam, dan kelembagaan yang terkait merupakan elemen yang diperlukan dalam proses produksi. Fungsi yang kedua adalah fungsi konservasi. Termasuk dalam fungsi ini adalah pemeliharaan elemen-elemen biofisik yang ada, seperti jaringan irigasi dan persawahan. Apabila elemen-elemen tersebut terpelihara maka fungsi konservasi dapat berlangsung dengan baik. Fungsi yang ketiga adalah pewarisan nilai-nilai budaya. Termasuk dalam fungsi tersebut adalah kapital sosial dan kearifan lokal yang mengatur hubungan manusia dengan manusia dan manusia dengan lingkungannya. Pengelolaan konflik dalam rangka pemanfaatan sumber daya merupakan salah satu elemen dari nilai-nilai budaya. Sosialisasi yang dimaksud disini adalah kegiatan penyuluhan yang dilakukan oleh petugas dalam rangka memberikan informasi kepada masyarakat tentang perlindungan lahan pertanian berkelanjutan. Berdasarkan wawancara dengan para petugas dalam hal ini adalah tim IPPT (Izin Perubahan Penggunaan Lahan) terdiri dari Bappeda, BPN, Distan, Disbun, DPU-ESDM, Bagian Hukum dan Tata Pemerintahan, yang merupakan petugas yang terkait langsung dengan perlindungan lahan pertanian berkelanjutan diperoleh gambaran bahwa sejauh ini kegiatan sosialisasi yang secara khusus diselenggarakan dalam rangka perlindungan lahan pertanian berkelanjutan belum pernah diadakan (Amalina et al., 2018; Masrukhin, 2019; Takim, 2020).

Tujuan kegiatan Sosialisasi ini adalah :

1. Mengenalkan konsep dari kebijakan Lahan Pertanian Pangan Berkelanjutan (LP2B).

2. Penguatan kelembagaan dan sistem informasi di kalangan petani pemilik lahan guna mendukung kebijakan LP2B.

Target khusus dari kegiatan ini adalah tumbuhnya kesadaran dari para petani pemilik lahan bahwa kedudukan mereka dalam mencegah alih fungsi lahan pertanian sangat strategis dalam 
mewujudkan kedaulatan pangan dan mampu berperan secara aktif dalam mewujudkan kebijakan Lahan Pertanian

Pangan Berkelanjutan (LP2B).

\section{B. PELAKSAAAN DAN METODE}

Mitra merupakan petani pemilik lahan yang dipilih berdasarkan rekomendasi Kepala Desa dan penyuluh pertanian yang memiliki kesadaran dan kemauan untuk mempertahankan lahan pertanian milik mereka. Langkah-langkah yang ditempuh dalam kegiatan sosialisasi LP2B adalah sebagai berikut :

1. Tahap penyamaan persepsi mengenai pentingnya menjaga fungsi lahan pertanian. Metoda yang dilakukan adalah menggunakan idea exploration mengunakan single character. Metode ini dipilih untuk menyampaikan fenomena-fenomena yang terjadi jika terjadi alih fungsi lahan pertanian.
2. Meningkatkan pengetahuan dan pemahaman petani pemilik lahan mengenai konsep LP2B. Kegiatan peningkatan pengetahuan dan pemahaman dasar mengenai konsep LP2B dengan metode ceramah. Metode ini dipilih untuk menyampaikan teori dan konsep yang penting untuk dimengerti peserta pelatihan. Materi teori mencakup konsep LP2B sesuai yang tercantum dalam UU Nomor 41 Tahun 2009 tentang Perlindungan Lahan Pertanian Pangan Berkelanjutan.

3. Evaluasi akhir dilakukan dalam rangka mengetahui tingkat pemahaman mitra terhadap materi yang diberikan, serta peningkatan aktualisasi wawasan yang dimiliki masingmasing sasaran.

Hubungan masalah dengan solusi pemecahan masalah yang ditawarkan dalam Pengabdian Masyarakat ini disajikan dalam tabel 1 .

Tabel 1. Hubungan Masalah dengan Solusi Pemecahan Masalah

\begin{tabular}{|c|c|c|c|}
\hline Masalah & Permasalahan & $\begin{array}{c}\text { Solusi Ditawarkan } \\
\text { (Metode) }\end{array}$ & Prosedur Kerja \\
\hline $\begin{array}{l}\text { Menumbuhkan } \\
\text { kesadaran bahayanya } \\
\text { alih fungsi lahan } \\
\text { pertanian }\end{array}$ & $\begin{array}{l}\text { Petani pemilik lahan belum } \\
\text { menyadari dampak negatif yang } \\
\text { dapat timbul dari alih fungsi lahan } \\
\text { pertanian }\end{array}$ & Brainstorming & $\begin{array}{l}\text { 1. Mempersiapkan } \\
\text { sarana dan } \\
\text { prasarana } \\
\text { pendampingan } \\
\text { 2. Melaksanakan } \\
\text { penyuluhan } \\
\end{array}$ \\
\hline $\begin{array}{l}\text { Bagaimana } \\
\text { meningkatkan } \\
\text { pengetahuan dan } \\
\text { pemahaman petani } \\
\text { pemilik lahan } \\
\text { terhadap konsep } \\
\text { LP2B }\end{array}$ & $\begin{array}{l}\text { Petani pemilik lahan belum } \\
\text { memahami konsep LP2B }\end{array}$ & $\begin{array}{l}\text { - Confirmmatif } \\
\text { Partisipatory } \\
\text { - Penyimpulan } \\
\text { konsep }\end{array}$ & 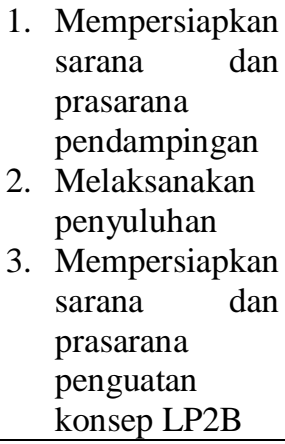 \\
\hline $\begin{array}{l}\text { Belum terbentuknya } \\
\text { supporting system } \\
\text { dalam implementasi } \\
\text { konsep LP2B }\end{array}$ & $\begin{array}{l}\text { Petani pemilik lahan belum } \\
\text { memahami sistem pendukung } \\
\text { konsep LP2B }\end{array}$ & $\begin{array}{l}\text { - Confirmmatif } \\
\text { Partisipatory } \\
\text { - Ekstraksi } \\
\text { Kaizen }\end{array}$ & 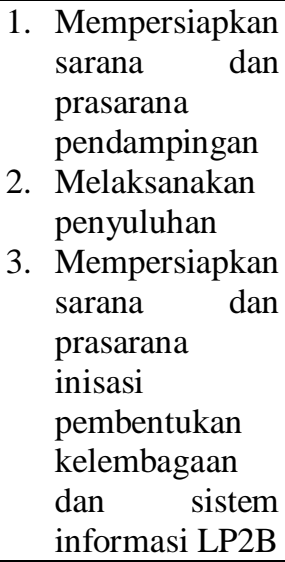 \\
\hline
\end{tabular}




\section{HASIL DAN PEMBAHASAN}

Lahan pertanian memiliki peran dan fungsi strategis bagi masyarakat Indonesia yang bercorak agraris. Sebagian besar penduduk Indonesia menggantungkan hidup pada sektor pertanian. Dalam posisi yang demikian lahan tidak saja memiliki nilai ekonomis, sosial bahkan secara filosofis lahan memiliki nilai religius (Amalina et al., 2018; Apriyanto \& Fikri, 2021). Konversi lahan pertanian menimbulkan dampak yang sangat besar terhadap ketahanan pangan. Lahan pertanian yang berubah fungsi akan mempunyai implikasi yang serius terhadap produksi pangan, fisik lingkungan, dan budaya masyarakat di sekitar lahan yang dikonversi tersebut. Permasalahan semakin kompleks, karena konversi lahan pertanian subur belum diimbangi oleh upaya yang sistematis untuk dapat mengembangkan lahan yang potensial. Konversi lahan pertanian pangan menyebabkan semakin sempitnya luas garapan usaha tani dan menurunnya tingkat kesejahteraan petani (Kusumastuti et al., 2018; Mustofa \& Bakce, 2019). Oleh karena itu, pengendalian konversi lahan pertanian pangan melalui perlindungan lahan pertanian pangan merupakan salah satu upaya untuk mewujudkan ketahanan dan kedaulatan pangan, dalam rangka meningkatkan kemakmuran dan kesejahteraan petani dan masyarakat (Fuad, Rachmiwati, Yusuf, 2014; Muryono \& Utami, 2020).

Dalam Undang-undang Nomor 41 tahun 2009 diatur bahwa lahan yang sudah ditetapkan sebagai lahan pertanian pangan berkelanjutan dilindungi dan dilarang dialihfungsikan. Lahan pertanian yang dilindungi hanya dapat dialihfungsikan untuk kepentingan umum, yang pelaksanaannya diatur dengan peraturan perundang-undangan. Pengalihfungsian lahan yang sudah ditetapkan dilakukan dengan syarat-syarat sebagai berikut :

- dilakukan kajian kelayakan strategis

- disusun rencana alih fungsi lahan

- dibebaskan kepemilikan haknya dari pemilik, dan

- disediakan lahan pengganti dari lahan yang dialihfungsikan.

Penetapan kawasan lahan pertanian berkelanjutan tidak lepas dari permasalahan alih fungsi lahan yang dihadapi oleh Kabupaten Indragiri Hilir satu dekade terakhir. Selama tujuh tahun sejak tahun 2004 sampai tahun 2011 telah terjadi alih fungsi lahan sawah di Kabupaten Indragiri Hilir seluas 1.270.267 hektar, dengan rata-rata pengurangan 181,467 hektar/tahun. Selain sawah, tegal atau ladang pun mengalami penurunan luas lahan sebesar 965,738 hektar dengan rata-rata pengurangan 136,677 hektar/tahun. Salah satu upaya yang ditempuh oleh Pemerintah Kabupaten
Indragiri Hilir untuk menyiasati terjadinya alih fungsi lahan pertanian adalah mengarahkan kawasan pertanian tanaman pangan menjadi kawasan pertanian pangan berkelanjutan sekitar 90\% dari total jumlah kecamatan di Kabupaten Indragiri Hilir (Hartono, 2020). Salah satunya adalah Kecamatan Batang Tuaka yang merupakan Pusat Pelayanan Lingkungan dan termasuk ke dalam Wilayah Pengembangan Banjaran dimana salah satu fungsinya adalah pengembangan kawasan pertanian (Gevisioner et al., 2014; Lapatandau et al., 2017; Prasada \& Rosa, 2018).

Dalam Undang Undang Republik Indonesia Nomor 41 tahun 2009 tentang Perlindungan Lahan Pertanian Pangan Berkelanjutan dijelaskan bahwa yang dimaksud dengan Lahan Pertanian Pangan Berkelanjutan adalah bidang lahan pertanian yang ditetapkan untuk dilindungi dan dikembangkan secara konsisten guna menghasilkan pangan pokok bagi kemandirian, ketahanan, dan kedaulatan pangan nasional. Sedangkan perlindungan lahan pertanian pangan berkelanjutan sendiri diartikan sebagai sistem dan proses dalam merencanakan dan menetapkan, mengembangkan, memanfaatkan dan membina, mengendalikan dan mengawasi lahan pertanian pangan dan kawasannya secara berkelanjutan.

Namun kebijakan untuk mengatasi alih fungsi lahan pertanian tersebut tidak didukung oleh pengetahuan dan pemahaman petani yang memiliki peran sentral terhadap konsep lahan pertanian pangan berkelanjutan. Penelitian yang telah dilaksanakan menunjukkan bahwa petani di wilayah kajian tidak mengetahui apalagi memahami mengenai konsep lahan pertanian pangan berkelanjutan sesuai Undang-Undang Nomor 41 Tahun 2009 (Apriyanto \& Fikri, 2021). Hal ini terjadi karena beberapa penyebab, diantaranya adalah :

1. Tidak adanya sosialisasi dari penyuluh pertanian mengenai konsep LP2B kepada para petani.

2. Bagi para petani, menjaga agar sawahnya tidak beralih fungsi bukanlah kewajiban mereka.

Setelah dilaksanakan sosialisasi mengenai konsep LP2B, terdapat perubahan dalam pola pikir mereka mengenai sawah yang mereka miliki(Ayunita et al., 2021; Takim, 2020).

Perubahan itu terjadi dalam bentuk :

1. Para petani menyadari bahwa sawah mereka memiliki peran penting dalam mewujudkan ketahanan pangan.

2. Bagaimanapun bentuk pengairan yang didapatkan, baik saluran irigasi ataupun hanya mengandalkan air hujan (sawah tadah hujan) memiliki kesempatan yang sama untuk dijadikan lahan pertanian pangan berkelanjutan dan mendapatkan berbagai insentif dari pemerintah dalam rangka menjaga agar sawah 
mereka tidak beralih fungsi (Amalina et al., 2018; Masganti et al., 2020).

Beberapa hambatan yang mungkin muncul dalam implementasi konsep LP2B di wilayah kajian adalah :

1. Adanya ancaman keberlanjutan lahan pertanian karena minimnya generasi muda yang berminat menjadi petani.

2. Belum adanya supporting system dalam mewujudkan lahan pertanian berkelanjutan yaitu sistem kelembagaan dan sistem informasi.

Sumberdaya lahan pertanian pangan yang berkelanjutan merupakan syarat untuk ketahanan pangan nasional. Ketersedian lahan pertanian pangan berkaitan erat dengan beberapa hal, yaitu : 1) Potensi sumberdaya lahan pertanian pangan, 2) Produktivitas lahan, 3) Fragmentasi lahan pertanian, 4) Skala luasan penguasaan lahan pertanian, 5) Sistem irigasi, 6) land rent lahan pertanian, 7) Konversi, 8) Pendapatan petani, 9) Kapasitas SDM pertanian serta 10) kebijakan di bidang pertanian. Penetapan lahan pertanian abadi merupakan salah satu opsi kebijakan yang oleh sebagian pihak dianggap paling tepat untuk mencegah proses alih fungsi lahan pertanian. Pada dasarnya lahan pertanian abadi adalah penetapan suatu kawasan sebagai daerah konservasi, atau perlindungan, khusus untuk usaha pertanian. Alih fungsi lahan pertanian ke penggunaan non pertanian dilarang dengan suatu ketetapan peraturan perundang-undangan.

Setelah dilaksanakan kegiatan sosialisasi mengenai konsep LP2B terhadap petani dan perangkat setempat, terdapat perubahan pola pikir dalam memandang alih fungsi lahan pertanian. Para petani menyadari bahwa mereka memiliki peran penting dalam mewujudkan perlindungan lahan pertanian pangan berkelanjutan, dan mereka mengetahui bahwa pemerintah melalui beberapa regulasi siap membantu petani dalam mempertahankan fungsi sawah mereka agar tidak berubah menjadi non sawah (Ashari, 2016).

Luaran yang dihasilkan dari kegiatan ini adalah :

1. Kelompok sasaran (petani) mengetahui konsep lahan pertanian pangan berkelanjutan.

2. Terjadinya peningkatan baseline pengetahuan dasar mengenai konsep LP2B.

3. Terbentuknya inisiasi supporting system dalam mewujudkan perlindungan terhadap lahan pertanian pangan berkelanjutan dalam bentuk inisiasi kelembagaan petani yang berfungsi juga sebagai media informasi sebagai langkah awal untuk membentuk sistem informasi seputar perlindungan lahan pertanian pangan berkelanjutan.

4. Pembuatan banner untuk mensosialisasikan kebijakan lahan pertanian pangan berkelanjutan.

Sebagai tindak lanjut untuk terus berperan aktif dalam mewujudkan kebijakan perlindungan terhadap lahan pertanian pangan berkelanjutan, dapat dilakukan sosialisasi mengenai kebijakan ini di tempat lain yang potensial secara konsisten dan terus menerus sehingga semakin banyak petani yang mengetahui dan memahami mengenai konsep dan kebijakan perlindungan terhadap lahan pertanian pangan berkelanjutan (Ashari, 2016; Edhy, 2021).

Menurut responden yang berhasil diwawancarai di lapangan diperoleh gambaran bahwa sebagian besar responden yaitu 88,19 \% mengatakan kegiatan sosialisasi perlindungan lahan pertanian berkelanjutan tidak pernah dilakukan. Sisanya 9.03\% mengatakan sosialisasi jarang dilakukan dan hanya $2,78 \%$ yang mengatakan jika sosialisasi tersebut sering dilakukan.

Menurut anggota masyarakat belum maksimalnya kegiatan sosialisasi perlindungan lahan pertanian pangan berkelanjutan ini disebabkan oleh belum adanya peraturan daerah yang mengatur tentang hal tersebut. Belum adanya perda menjadi hambatan dalam kegiatan sosialisasi karena lahan pertanian yang dilindungi belum ditetapkan, sehingga tidak ada payung hukum yang jelas seandainya terjadi pelanggaran, demikian pula dalam menyampaikan informasi lahan-lahan mana yang dijadikan lahan yang dilindungi.

\section{PENUTUP \\ Simpulan}

Setelah dilakukan sosialisasi mengenai konsep dan kebijakan perlindungan terhadap lahan pertanian berkelanjutan, para petani menyadari bahwa sawah mereka tidak terbatas pada nilai ekonomi, namun memiliki peran penting dalam mewujudkan ketahanan pangan, lebih jauhnya terhadap perwujudan kedaulatan pangan, sehingga diharapkan laju alih fungsi lahan pertanian (sawah) dapat ditekan sejalan dengan peningkatan pengetahuan dan pemahaman petani mengenai konsep dan kebijakan perlindungan lahan pertanian pangan berkelanjutan.

\section{Saran}

Sosialisasi perlu dilakukan secara intensif dan kontinyu, mengingat masih banyaknya kejadian konversi lahan pertanian. Dengan sosialisasi diharapkan masyarakat mengetahui tentang perlindungan lahan pertanian dan memahami maksud dan tujuannya, sehingga dapat menyadarkan masyarakat untuk tidak lagi mengkonversi lahan pertaniannya. Jika dapat dilaksanakan secara efektif maka pastilah konversi lahan di kawasan konservasi tersebut tidak akan terjadi. Secara teoritis, dengan asumsi dapat diefektifkan, opsi kebijakan inilah yang paling ampuh untuk mencegah konversi lahan pertanian.

Untuk mencegah dan mengendalikan kegiatan konversi lahan pertanian, sejauh ini pemerintah lebih terfokus pada pendekatan hukum yaitu dengan membuat peraturan dan perundang- 
undangan yang bersifat melarang konversi lahan pertanian, khususnya lahan sawah beririgasi teknis. Dalam pelaksanaannya terdapat dua jenis acuan instrumen hukum yang digunakan yaitu: (1) RUTRW yang mengatur lokasi kegiatan pembangunan termasuk lahan pertanian yang dapat dikonversi ke penggunaan di luar pertanian dan (2) peraturan-peraturan yang mengatur prosedur pelaksanaan konversi lahan pertanian.

\section{E. DAFTAR PUSTAKA}

Amalina, A., Binasasi, S. D., \& Purnaweni, H. (2018). Formulasi Kebijakan Perlindungan Lahan Pertanian Pangan Berkelanjutan Di Kabupaten Karawang. Gema Publica, 3(2), 92. https://doi.org/10.14710/gp.3.2.2018.92102

Anonim. (2013). Indragiri hilir. BPS, INHIL.

Apriyanto, M., Fikri, K. M. S. N. S., Siregar, V. A., Azhar, A., Mulono Apriyanto, Fikri, K. M. S. N. S., Siregar, V. A., Jamri, \& Azhar, A. (2020). Penyuluhan Tentang Peremajaan Kelapa Sawit dan Legalitas Lahan Di Kecamatan Kempas Kabupaten Indragiri Hilir. ARBITRASE: Journal of Economics and Accounting, 1(1), 1-6. https://doi.org/10.31219/osf.io/7j4sy

Apriyanto, M., \& Fikri, K. N. S. (2021). Naskah Akademik LP2B Kabupaten Indragiri Hilir.

Apriyanto, M., Fikri, K. N. S., \& Azhar, A. (2021). Pendampingan Santri untuk Penurunan Tingkat Pelanggaran Lalu Lintas. Magistrorum et Scholarium: Jurnal Pengabdian Masyarakat, 1(2), 238-247. https://doi.org/10.24246/jms.v1i22020p238247

Ashari, N. (2016). Tinjauan tentang Alih Fungsi Lahan Sawah ke Non Sawah dan Dampaknya di Pulau Jawa. Forum Penelitian Agro Ekonomi, 21(2), 83. https://doi.org/10.21082/fae.v21n2.2003.8398

Ayunita, K. T., Putu Widiati, I. A., \& Sutama, I. N. (2021). Pengendalian Alih Fungsi Lahan Pertanian Pangan Berkelanjutan. Jurnal Konstruksi Hukum, 2(1), 160-164. https://doi.org/10.22225/jkh.2.1.2987.160164

Azhar, A., Maryanto, M., \& Siregar, V. A. (2020). Penanganan Tindak Pidana Kejahatan Premanisme di Wilayah Hukum Indragiri Hilir. Logika : Journal of Multidisciplinary Studies, 11(02), 79-86. https://doi.org/10.25134/logika.v11i02.3121

Azhar, A., Maryanto, V. A. S., Apriyanto, M., \& Samosir, A. (2020). Penanganan Kejahatan Preman Pada Wilayah Hukum Polisi Resort Indragiri Hilir. Res Nullius Law Journal, 2(2), 158-164.

Djatmiko, A., Rantini, R., \& Priyandoko, Z.
(2019). Sosialisasi Konsep Lahan Pertanian Pangan Berkelanjutan di Desa Cikalong, Kecamatan Cimaung, Kabupaten Bandung. Jurnal Pengabdian Kepada Masyarakat, 9(1), https://doi.org/10.30999/jpkm.v9i1.410

Edhy, S. (2021). Petunjuk-Teknis-RekomendasiPerlindungan-Lahan-Pertanian-Pangan-

Berkelanjutan (p. Kementrian Pertanian, Direktur Jendreal Prasarana).

Fuad, Rachmiwati, Yusuf, dan I. (2014). DAMPAK KONVERSI LAHAN TERHADAP KECUKUPAN DAN KETAHANAN PANGAN DI PROVINSI RIAU. Jurnal Dinamika Pertanian, XXIX, 245-254.

Gevisioner, Dan, \& Riza, S. (2014). Kegagalan Perlindungan Lahan Pertanian Pangan di Provinsi Riau Failure Protection Of Food Agricultural Land in the Riau Province. Prosiding Seminar NasionalLahan Suboptimal, September, 1-8.

Hartono. (2020). Kabupaten Indragiri Hilir Dalam Angka 2020. In BPS Kabupaten Indragiri Hilir.

Kusumastuti, A. C., M. Kolopaking, L., \& Barus, B. (2018). FAKTOR YANG MEMPENGARUHI ALIH FUNGSI LAHAN PERTANIAN PANGAN DI KABUPATEN PANDEGLANG. Sodality: Jurnal Sosiologi Pedesaan, 6(2), 131-136. https://doi.org/10.22500/sodality.v6i2.23234

Lapatandau, Y. A., Rumagit, G. A. J., \& Pakasi, C. B. D. (2017). Alih Fungsi Lahan Pertanian Di Kabupaten Minahasa Utara. AgriSosioekonomi, 13(2A), 1-8. https://doi.org/10.35791/agrsosek.13.2a.2017 .16548

Masganti, M., Anwar, K., \& Susanti, M. A. (2020). Potensi dan Pemanfaatan Lahan Gambut Dangkal untuk Pertanian. Jurnal Sumberdaya Lahan, 11(1), 43=52. https://doi.org/10.21082/jsdl.v11n1.2017.4352

Masrukhin. (2019). PERLINDUNGAN LAHAN PERTANIAN PANGAN BERKELANJUTAN DALAM PERSPEKTIF ALIH FUNGSI LAHAN DI KABUPATEN CIREBON. HERMENEUTIKA, 3(2), 370-373.

Muryono, S., \& Utami, W. (2020). PEMETAAN POTENSI LAHAN PERTANIAN PANGAN BERKELANJUTAN GUNA MENDUKUNG KETAHANAN PANGAN. BHUMI: Jurnal Agraria Dan Pertanahan Received:, 6(2), 201-218.

Mustofa, R., \& Bakce, R. (2019). Potensi Konflik Lahan Perkebunan Kelapa Sawit. Unri Conference Series: Agriculture and Food Security, $\quad$ 1, 58-66. https://doi.org/10.31258/unricsagr.1a8 
Novyar Satriawan Fikri, K., \& Azhar, A. (2020). Implementation of Discipline Policy for Civil Servants in Indragiri Hilir Regency Post Covid Pandemic 19. Proceedings of the 5 th NA International Conference on Industrial Engineering and Operations Management Detroit, Michigan, USA, August 10 - 14, 2020, 2188-2191.

Prasada, I. M. Y., \& Rosa, T. A. (2018). Dampak Alih Fungsi Lahan Sawah Terhadap Ketahanan Pangan Di Daerah Istimewa Yogyakarta. Jurnal Sosial Ekonomi Pertanian, 14(3), 210-224. https://doi.org/10.20956/jsep.v14i3.4805

Takim, M. H. (2020). Perlindungan Hukum Lahan Pertanian Pangan Berkelanjutan (PLP2B) Di Kabupaten Gresik Terhadap Ijin Usaha dan Industri. Airlangga Development Journal, 2(2),

https://doi.org/10.20473/adj.v2i2.18070 